\title{
Impacts of Venturi Turbulent Mixing on the Size Distribution of Sodium Chloride and Dioctyl- Phthalate Aerosols
}

\author{
Meng-Dawn Cheng \\ Thomas Wainman \\ John Storey
}

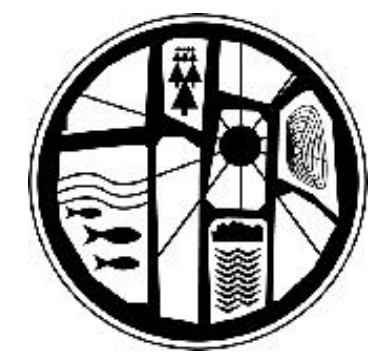




\title{
DOCUMENT AVAILABILITY
}

Reports produced after January 1, 1996, are generally available free via the U.S. Department of Energy (DOE) Information Bridge.

Web site http://www.osti.gov/bridge

Reports produced before January 1, 1996, may be purchased by members of the public from the following source.

\author{
National Technical Information Service \\ 5285 Port Royal Road \\ Springfield, VA 22161 \\ Telephone 703-605-6000 (1-800-553-6847) \\ TDD 703-487-4639 \\ Fax 703-605-6900 \\ E-mail info@ntis.fedworld.gov \\ Web site http://www.ntis.gov/support/ordernowabout.htm
}

Reports are available to DOE employees, DOE contractors, Energy Technology Data Exchange (ETDE) representatives, and International Nuclear Information System (INIS) representatives from the following source.

Office of Scientific and Technical Information

P.O. Box 62

Oak Ridge, TN 37831

Telephone 865-576-8401

Fax 865-576-5728

E-mail reports@adonis.osti.gov

Web site http://www.osti.gov/contact.html

This report was prepared as an account of work sponsored by an agency of the United States Government. Neither the United States Government nor any agency thereof, nor any of their employees, makes any warranty, express or implied, or assumes any legal liability or responsibility for the accuracy, completeness, or usefulness of any information, apparatus, product, or process disclosed, or represents that its use would not infringe privately owned rights. Reference herein to any specific commercial product, process, or service by trade name, trademark, manufacturer, or otherwise, does not necessarily constitute or imply its endorsement, recommendation, or favoring by the United States Government or any agency thereof. The views and opinions of authors expressed herein do not necessarily state or reflect those of the United States Government or any agency thereof. 

Environmental Sciences Division

\title{
IMPACTS OF VENTURI TURBULENT MIXING ON \\ THE SIZE DISTRIBUTIONS OF SODIUM CHLORIDE AND DIOCTYL-PHTHALATE AEROSOLS
}

\author{
Meng-Dawn Cheng \\ Environmental Sciences Division \\ Oak Ridge National Laboratory
}

Thomas Wainman

Oak Ridge Associated Universities

John Storey

Engineering Technology Division

Oak Ridge National Laboratory

Environmental Sciences Division

Publication No. 5008

Date Published: August 2000

Prepared for the

U.S. Department of Energy

Office of Transportation Technology

under Budget and Reporting code EE0503000

Prepared by

OAK RIDGE NATIONAL LABORATORY

Oak Ridge, Tennessee 37831 managed by

UT-BATTELLE, LLC

for the

U.S. DEPARTMENT OF ENERGY

under contract DE-AC05-00OR22725 



\section{CONTENTS}

LIST OF FIGURES $\ldots \ldots \ldots \ldots \ldots \ldots \ldots \ldots \ldots \ldots \ldots \ldots \ldots \ldots \ldots \ldots \ldots \ldots \ldots$

LIST OF TABLES $\ldots \ldots \ldots \ldots \ldots \ldots \ldots \ldots \ldots \ldots \ldots \ldots \ldots \ldots \ldots \ldots \ldots \ldots \ldots \ldots$

ACKNOWLEDGMENTS $\ldots \ldots \ldots \ldots \ldots \ldots \ldots \ldots \ldots \ldots \ldots \ldots \ldots \ldots \ldots \ldots$ ix

EXECUTIVE SUMMARY $\ldots \ldots \ldots \ldots \ldots \ldots \ldots \ldots \ldots \ldots \ldots \ldots \ldots \ldots \ldots \ldots \ldots \ldots \ldots$

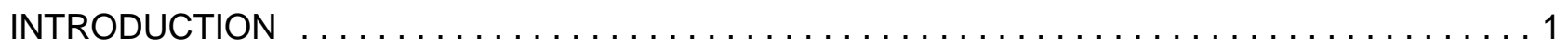

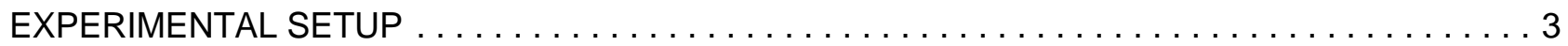

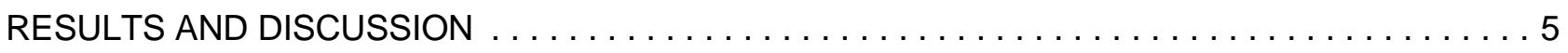

SOLID SODIUM CHLORIDE $(\mathrm{NaCl})$ PARTICLES $\ldots \ldots \ldots \ldots \ldots \ldots \ldots \ldots \ldots \ldots \ldots$

DIOCTYL-PHTHALATE (DOP) PARTICLES $\ldots \ldots \ldots \ldots \ldots \ldots \ldots \ldots \ldots$

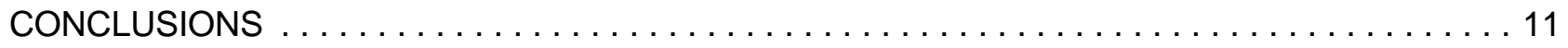

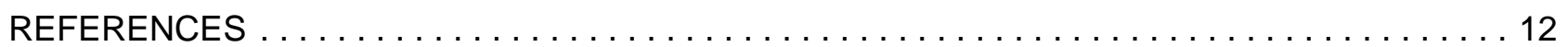





\section{LIST OF FIGURES}

Fig. 1 Schematic of the mini-diluter system used $\ldots \ldots \ldots \ldots \ldots \ldots \ldots \ldots$

Fig. 2 Aerosol generation and sampling configuration $\ldots \ldots \ldots \ldots \ldots \ldots \ldots$

Fig. 3 Particle size distribution generated by nebulizing $98 \pm 6 \mathrm{~nm}$ polystyrene

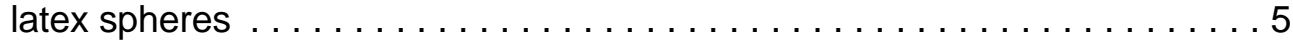

Fig. 4 Particle size distribution for aerosol generated by nebulizing a $0.5 \%$ (w/v) $\mathrm{NaCl} / \mathrm{H}_{2} \mathrm{O}$ Solution $\ldots \ldots \ldots \ldots \ldots \ldots \ldots \ldots \ldots \ldots \ldots \ldots \ldots \ldots \ldots \ldots$

Fig. 5 Coefficient of variation for each particle size range is plotted for both the pre and post dilutor $\mathrm{NaCl}$ aerosol data $\ldots \ldots \ldots \ldots \ldots \ldots$

Fig. 6 A plot of the difference in the coefficient of variation between the post and pre dilutor $\mathrm{NaCl}$ aerosol data in Fig. $5 \ldots \ldots \ldots \ldots \ldots \ldots$

Fig. 7 Particle size distribution for aerosol generated by nebulizing a $0.03 \%$ $(\mathrm{v} / \mathrm{v}) \mathrm{DOP} /$ propanol solution $\ldots \ldots \ldots \ldots \ldots \ldots \ldots \ldots \ldots \ldots \ldots \ldots \ldots \ldots \ldots \ldots$

Fig. 8 Coefficient of variation for each particle size range plotted for both the pre and post dilutor DOP aerosol data $\ldots \ldots \ldots \ldots \ldots \ldots \ldots \ldots \ldots \ldots \ldots$ 



\section{LIST OF TABLES}

Table 1 Design specification of the mini-dilution system $\ldots \ldots \ldots \ldots \ldots \ldots$

Table 2 Summary statistics of DOP and $\mathrm{NaCl}$ particle size distributions $\ldots \ldots \ldots 7$ 



\section{ACKNOWLEDGMENTS}

Thomas Wainman of the Oak Ridge Associated University was supported in part by an appointment to the Oak Ridge National Laboratory Postdoctoral Research Associates Program administered jointly by the Oak Ridge National Laboratory and the Oak Ridge Institute for Science and Education. Thang Dam, a graduate student, of the Mechanical Engineering Department at University of Tennessee assisted in performing the experiments. Professor Da-Ren Chen of the Particle Technology Laboratory at the University of Minnesota provided a critical review of the turbulent mixing process for the draft manuscript and many useful suggestions for improvement of this technical manual. Dr. Dennis Jennings of the Abott Laboratory provided extremely useful insight into the Poisson counting process and statistics and comments on the incompatibility between the Poisson statistics and the coefficient of variation. He convinced the author (MDC) that "looking partially at a picture is worse than not looking at it" implying it can be very dangerous to trust only partial statistical analysis. 



\section{EXECUTIVE SUMMARY}

Internal combustion engines are a major source of airborne particulate matter (PM). The size of the engine $\mathrm{PM}$ is in the sub-micrometer range. The number of engine particles per unit volume is high, normally in the range of $10^{12}$ to $10^{14}$. To measure the size distribution of the engine particles dilution of an aerosol sample is required. A diluter utilizing a venturi ejector mixing technique is commercially available and tested. The purpose of this investigation was to determine if turbulence created by the ejector in the mini-dilutor changes the size of particles passing through it.

The results of the $\mathrm{NaCl}$ aerosol experiments show no discernible difference in the geometric mean diameter and geometric standard deviation of particles passing through the ejector. Similar results were found for the DOP particles. The ratio of the total number concentrations before and after the ejector indicates that a dilution ratio of approximately 20 applies equally for $\mathrm{DOP}$ and $\mathrm{NaCl}$ particles. This indicates the dilution capability of the ejector is not affected by the particle composition. The statistical analysis results of the first and second moments of a distribution indicate that the ejector may not change the major parameters (e.g., the geometric mean diameter and geometric standard deviation) characterizing the size distributions of $\mathrm{NaCl}$ and DOP particles.

However, when the skewness was examined, it indicates that the ejector modifies the particle size distribution significantly. The ejector could change the skewness of the distribution in an unpredictable and inconsistent manner. Furthermore, when the variability of particle counts in individual size ranges as a result of the ejector is examined, one finds that the variability is greater for DOP particles in the size range of $40-150 \mathrm{~nm}$ than for $\mathrm{NaCl}$ particles in the size range of 30 to $350 \mathrm{~nm}$. The numbers or particle counts in this size region are high enough that the Poisson counting errors are small $(<10 \%)$ compared with the tail regions. This result shows that the ejector device could have a higher bin-to-bin counting uncertainty for "soft" particles such as DOP than for a solid dry particle like $\mathrm{NaCl}$. The results suggest that it may be difficult to precisely characterize the size distribution of particles ejected from the mini-dilution system if the particle is not solid. 



\section{INTRODUCTION}

With changes in diesel engine design aimed at reducing exhaust emissions, it is important to characterize the impact of the design changes on emissions in order to assess their impact on human health and the environment. Particulate emissions are of concern because of their known adverse impacts in both of these areas (e.g., USEPA, 1997; Dockery and Pope, 1996; Pope, 2000 and references therein). Diesel particles are typically in the sub-micrometer diameter range making it difficult to characterize their physiochemical properties (e.g., size, light scattering, and chemical composition) in real time.

Characterization of the sizes of ultrafine airborne particles of diameter from $1 \mathrm{~nm}$ to $500 \mathrm{~nm}$ requires special techniques. An aerosol particle enters into an electric field, carrying $n$ electric charges, experiences an electrical force, causing it to move through the gas in which it is suspended. The resulting drag force on the particle is equated to the electrical force that permits the determination of the electrical mobility of the particle. A commercially available instrument utilizes the electrical mobility of the ultrafine particles to measure the diameter of aerosol particles in a continuous manner (TSI, 1999). Knutson and Whitby (1975) describe the theory of electrical mobility of particles in detail. Size-classified particles are transferred to a particle sensor to determine the particle concentration.

The most commonly used particle sensor is a condensation particle counter (CPC). An aerosol particle is saturated with alcohol vapor as it passes over a heated pool of alcohol in a CPC. The vapor-saturated aerosol then flows into a cold condenser, where it is cooled by thermal diffusion. The alcohol condenses onto the particles and the particles grow into droplets large enough to be counted optically. CPC can detect aerosol concentration of 10,000 particles $\mathrm{cm}^{-3}$ or greater, but aerosol concentrations in diesel exhaust are typically in the range of $10^{12}$ to $10^{14}$ particles $\mathrm{cm}^{-3}$ exceeding the working range of current CPC making it necessary to dilute the aerosol prior to sampling.

The dilution process may produce adverse conditions under which particle sizes may be altered through a number of processes such as condensation and coagulation. These processes can artificially cause a change in the aerosol size distribution before the aerosol is measured, yielding a non-representative measurement. A mini-dilution system has been designed to achieve a rapid dilution of diesel exhaust in dry air (Abdul-Khalek et al., 1998) minimizing possible change in the particle size distribution to be measured. A mini-dilution system is shown in Fig. 1. A critical orifice (\#4 in Fig. 1) is used to provide a constant-mass aerosol flow rate into an ejector (\#5 in Fig. 1). A venturi throat is used to provide a second flow to drive the pumping force of the aerosol sample. The aerosol flow is mixed with a second flow (from the air supply \#9 in Fig. 1) into the ejector (\#5) where aerosol is to be mixed. Such a rigorous mixing is turbulent, which causes concern about possible particle breakup and alteration of the original particle size distribution. The design and operating parameters of the ejector are shown in Table 1. 


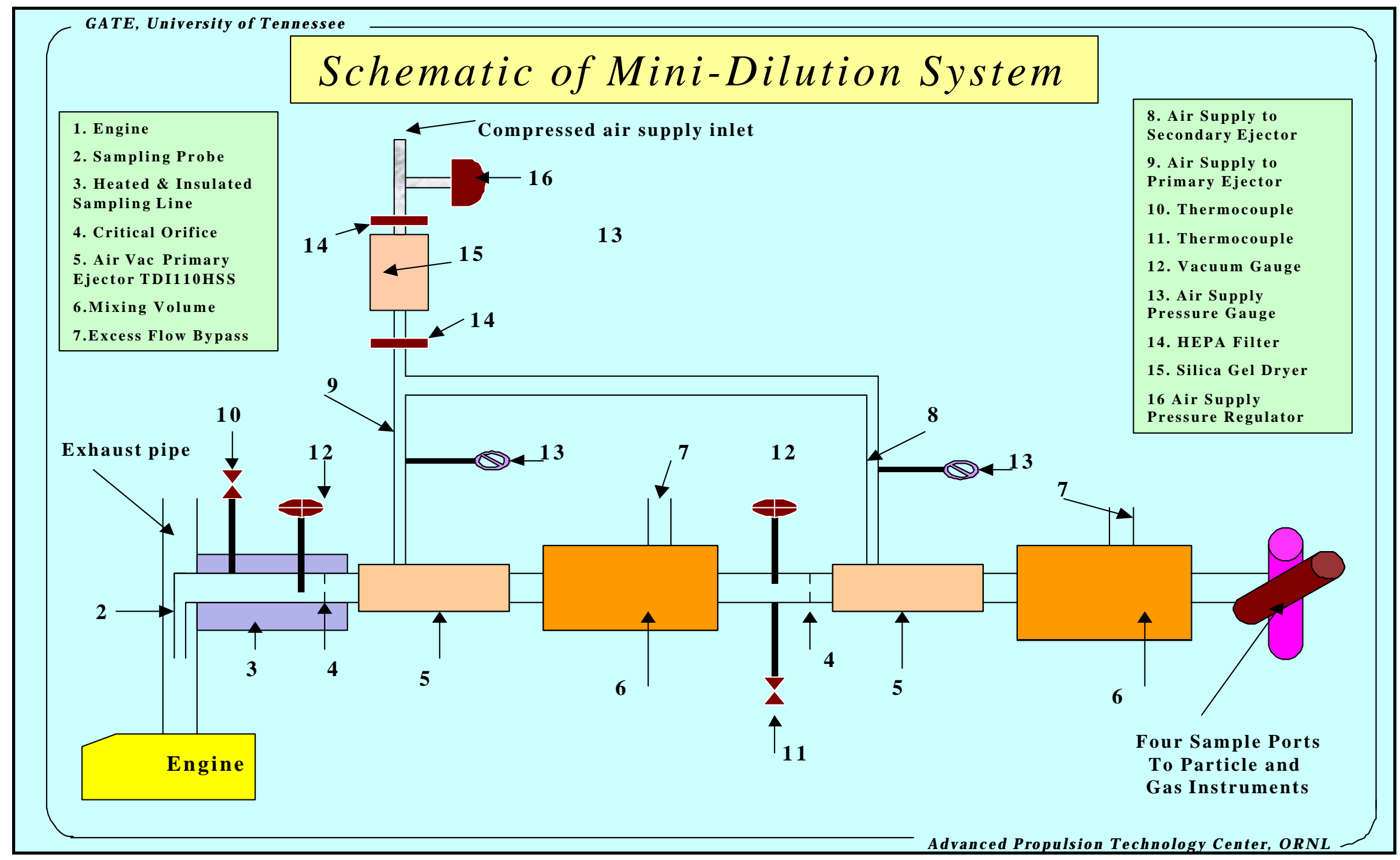

Fig. 1. Schematic of the mini-dilution system used. 
Table 1. Design specification of the mini-dilution system

\begin{tabular}{|c|c|c|c|c|c|c|c|c|c|}
\hline \multirow{3}{*}{\multicolumn{2}{|c|}{ Mini-Dilution System Par }} & \multicolumn{4}{|c|}{ meters } & \multirow{2}{*}{\multicolumn{2}{|c|}{ Flow rate }} & \multirow{2}{*}{\multicolumn{2}{|c|}{ Residence Time }} \\
\hline & & \multirow{2}{*}{$\frac{\text { Le }}{\mathrm{mm}}$} & & \multirow{2}{*}{\multicolumn{2}{|c|}{\begin{tabular}{l|r}
\multicolumn{2}{c}{ Inside Diameter } \\
$\mathrm{mm}$
\end{tabular}}} & & & & \\
\hline & & & \multirow{2}{*}{ in } & & & SLPM & SI3PM & \multirow{2}{*}{$\begin{array}{l}\mathrm{ms} \\
11\end{array}$} & \multirow{2}{*}{$\begin{array}{c}\text { ins } \\
0.4334\end{array}$} \\
\hline Sampling & PTL & 100 & & 4.5 & 0.1773 & 9 & 549.2133 & & \\
\hline Probe & UMN & 55 & 2.17 & 4.5 & 0.1773 & $\overline{9}$ & 549.2133 & 6 & 0.2364 \\
\hline \multirow{2}{*}{$\begin{array}{l}\text { Sampling } \\
\text { Line }\end{array}$} & $\begin{array}{l}\text { PTL } \\
\end{array}$ & 1500 & 59.10 & 4.5 & 0.1773 & 9 & 549.2133 & 159 & 6.2646 \\
\hline & UMN & 1500 & 59.10 & 4.5 & 0.1773 & 9 & 549.2133 & 159 & 6.2646 \\
\hline
\end{tabular}

\begin{tabular}{|l|c|c|c|c|c|c|c|c|r|}
\cline { 3 - 10 } \multicolumn{2}{c|}{} & \multicolumn{2}{c|}{ Length } & \multicolumn{2}{c|}{ Inside Diameter } & \multicolumn{3}{c|}{ Flow Rate } \\
\cline { 3 - 11 } \multicolumn{2}{c|}{} & Overall & 500 & 19.70 & Overall & 20 & in & \multicolumn{2}{c|}{ SI3PM } \\
\hline
\end{tabular}

\begin{tabular}{|l|c|c|c|c|}
\cline { 3 - 5 } \multicolumn{1}{c|}{} & \multicolumn{2}{c|}{ PTL } & \multicolumn{2}{c|}{ UMN } \\
\cline { 3 - 6 } \multicolumn{1}{c|}{} & $\mathrm{ms}$ & ins & ms & ins \\
\hline Residence time between Primary and Secondary: & 14 & 0.5516 & 594 & 23.4036 \\
\hline Residence time between Secondary and Particle Instruments: & 474 & 18.6756 & 1500 & 59.1 \\
\hline
\end{tabular}

UMN: University of Minnesota

PTL:Perkins Technology Limited

Conversion Factor
\begin{tabular}{|c|c|}
\hline $\mathrm{mm}$ & in \\
\hline 1 & 0.0394 \\
\hline
\end{tabular}

\begin{tabular}{|c|c|c|}
\hline liter & $\mathrm{m} 3$ & in3 \\
\hline 1 & 0.001 & 61.0237 \\
\hline
\end{tabular}

To date the dilutor has been used in experiments to characterize particulate emissions at different engine operating conditions (Abdul-Khalek et al., 1998; Graskow et al., 1999; and Graskow et al., 1998) but to the author's knowledge, there is no published study that fully characterizes the turbulent mixing effect on the particle size distribution. Since there are plans to use this dilutor in diesel exhaust particle toxicity experiments currently funded by the ORNL Laboratory Director Research and Development Program Office (Project title: Cellular Toxicity of Nanoparticles), it is essential to characterize the impacts of the dilutor itself on the particle size distribution.

\section{EXPERIMENTAL SETUP}

The experimental set configuration is shown in Fig. 2. The aerosol was generated using a TSI Model 3076 constant-output non-recycling nebulizer. After exiting the nebulizer, the aerosol was passed through a copper condenser packed in ice and then into a tee where it was diluted with dry HEPA filtered dilution air from the building air supply system. The dilution air supply was free of particles as small as $1.9 \mathrm{~nm}$, the smallest diameter we are capable of measuring using the TSI Scanning Mobility Particle Analyzer (SMPS). The aerosol flow rate was $3 \mathrm{~L} \mathrm{~min}^{-1}$ into the sampling manifold and the dilution airflow rate was $20 \mathrm{~L} \mathrm{~min}^{-1}$. After exiting the dilution tee the aerosol entered a 5-foot long sampling manifold with a 4-inch inner diameter. The sampling manifold has 4 ports spaced one foot apart. The mini-dilutor inlet was connected to one of the ports and sampled the aerosol at a rate of $8.4 \mathrm{~L} \mathrm{~min}^{-1}$ or lpm. 


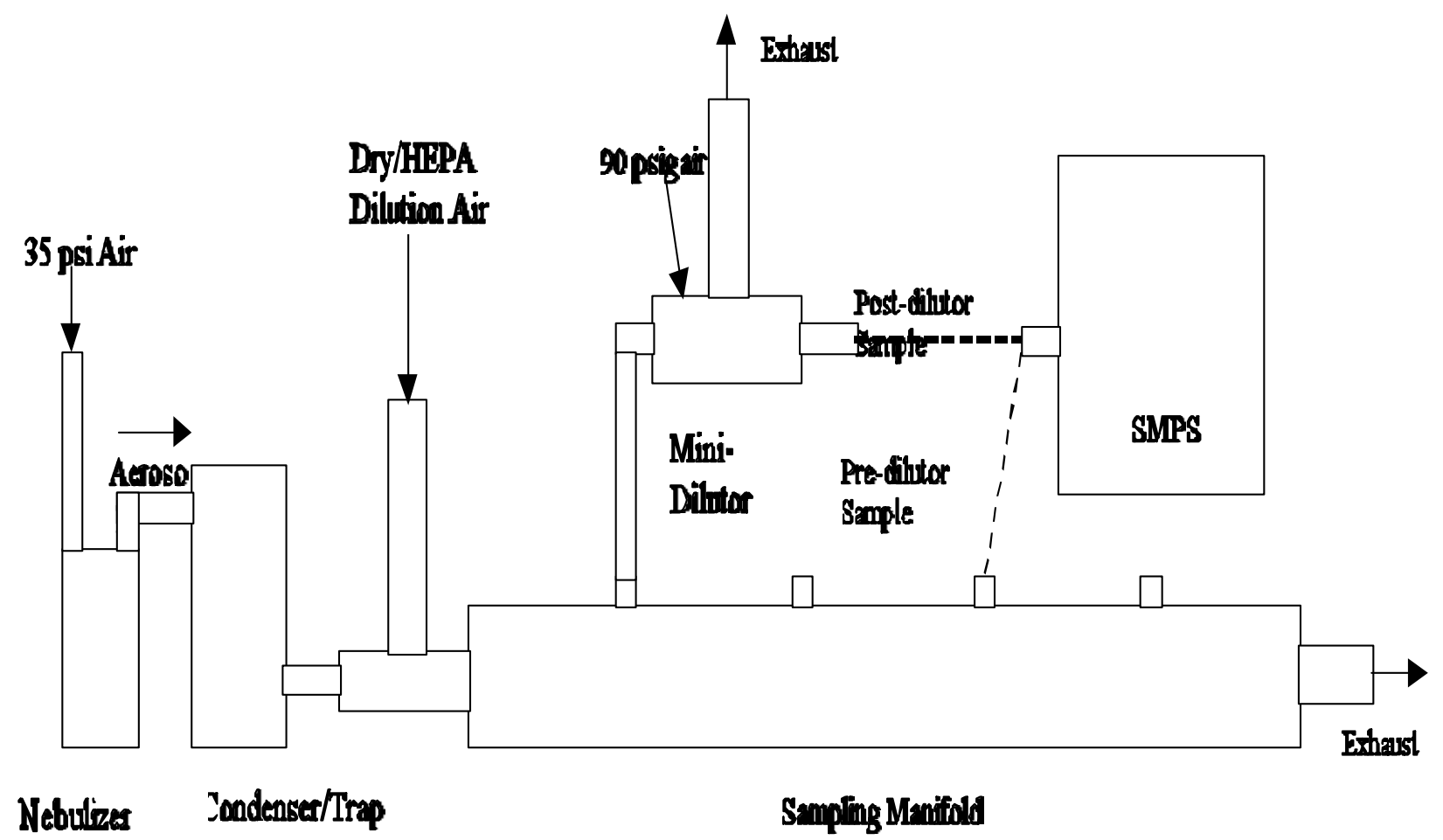

Fig. 2. Aerosol generation and sampling configuration. The dotted lines on the SMPS represent the two possible aerosol sampling points. The SMPS was connected to the sampling manifold to collect the pre dilutor sample and to the dilutor itself to collect the post dilutor sample.

The particle concentration and size distribution data were collected using a TSI Model 3936 Scanning Mobility Particle Sizer (SMPS) equipped with a model 3081 Differential Mobility Analyzer (DMA) and a TSI Model 3025A Condensation Particle Counter (CPC). The SMPS sheath flow rate was operated at $6 \mathrm{lpm}$ and the aerosol flow was $0.6 \mathrm{lpm}$. The up scan time was 120 seconds and the down scan time was 60 seconds. The SMPS instrument inlet was connected to a port on the sampling manifold when sampling for the "pre-diluter" data. The inlet was switched and connected to the "post-sampling" port when taking the "post-diluter" data.

Polystyrene Latex (PSL) suspension were purchased from the Duke Chemicals and used as it was. The PSL particles of a nominal diameter of $98 \pm 6 \mathrm{~nm}$ were diluted to $0.02 \%(\mathrm{v} / \mathrm{v})$ and nebulized to produce particles of known size for evaluating the performance and verifying the accuracy of the aerosol generation (Fig. 2) and TSI SMPS measurement systems. The system test result is shown in Fig. 3. The long differential mobility analyzer (DMA) (TSI model 3081) was used in the SMPS.

The nebulizer, in two separate sets of experiment, was used to generate two different types of aerosols. The number concentration and size distribution of the aerosol particles were measured before and after the particles being passed through the dilutor. An aerosol consisting of dry solid particles was generated from a solution of $0.5 \%(\mathrm{w} / \mathrm{v})$ sodium chloride $(\mathrm{NaCl})$ in water. An aerosol consisting of oil droplets was generated from $0.03 \%(\mathrm{v} / \mathrm{v})$ dioctyl-phthalate (DOP) in 2-propanol. 


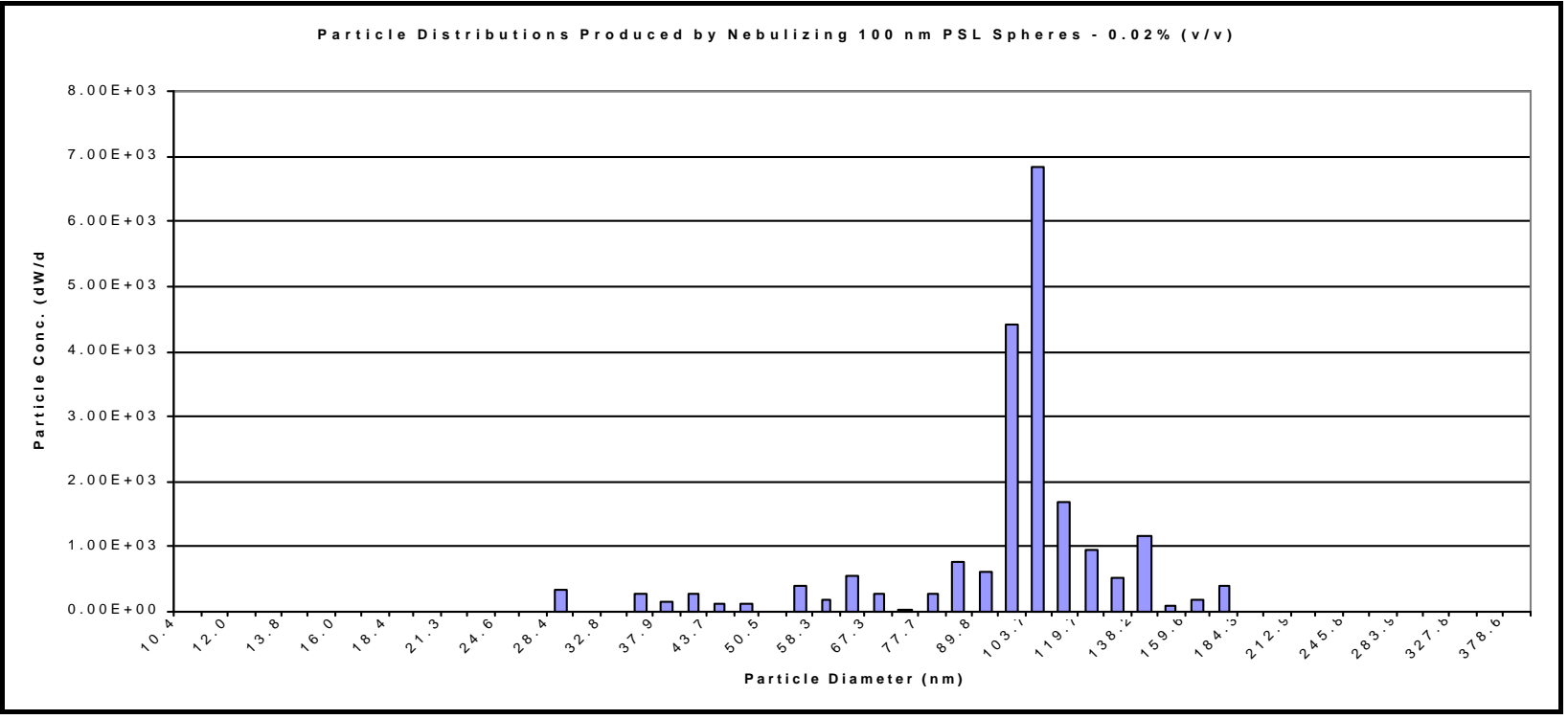

Fig. 3. Particle size distribution generated by nebulizing $98 \pm 6 \mathrm{~nm}$ polystyrene latex spheres. The two major peaks at 96 and $103 \mathrm{~nm}$ are within the expected range indicating that the generation and sampling systems were functioning properly.

The statistical figures of merit used in the comparison of particle size distributions obtained before and after the ejector are:

1. The median particle size in $\mathrm{nm}$ of $\mathrm{M}$ repeated measurements,

2. The geometric mean particle size in $\mathrm{nm}$ of $\mathrm{M}$ repeated measurements,

3. The geometric standard deviation of $\mathrm{M}$ repeated measurements,

4. The total number concentration in $\mathrm{cm}^{-3}$ of $\mathrm{M}$ repeated measurements,

5. The skewness of the repeated measurements,

6. Coefficient of variation of $\mathrm{dW} / \mathrm{d} \log \mathrm{D}_{\mathrm{p}}$ (normalized count) across $\mathrm{M}$ repeated measurements.

Other non-parametric statistics could have been examined for a detailed characterization of a particle size distribution. However, the authors feel that these 6 indices would provide sufficient information to evaluate the impacts of the ejector on the particle size distribution. Detailed statistical characterization of the particle size distributions obtained is not needed.

\section{RESULTS AND DISCUSSION}

The particle size distribution resulting form nebulizing the PSL particles is shown in Fig. 3. The two major peaks are at 96 and $103 \mathrm{~nm}$, within the certified range. The absence of any other 
major peaks is an indication that the aerosol was well dried, and the aerosol generation system is performing correctly as designed. Use of the PSL aerosols confirms that the aerosol delivery and measurement systems were functioning as expected.

\section{SOLID SODIUM CHLORIDE (NaCl) PARTICLES}

The particle size distributions for both the pre and post dilutor concentrations of the $\mathrm{NaCl}$ aerosol are shown in Fig. 4. The data is the average of three sample runs and the error bars represent the range [= max value - min value of the 3 samples] of the data for each particle size. As can be seen in Table 2, both distributions are symmetrical and are centered at around $77 \mathrm{~nm}$ (the geometric mean). The geometric standard deviations are approximately 1.7 indicating a

polydisperse aerosol. No significant changes in the geometric mean size and geometric standard deviation and the median diameter are found for particles passing through the ejector in the minidilution system. The dilution however decreases the total number concentration of particle by approximately 20 times as expected.

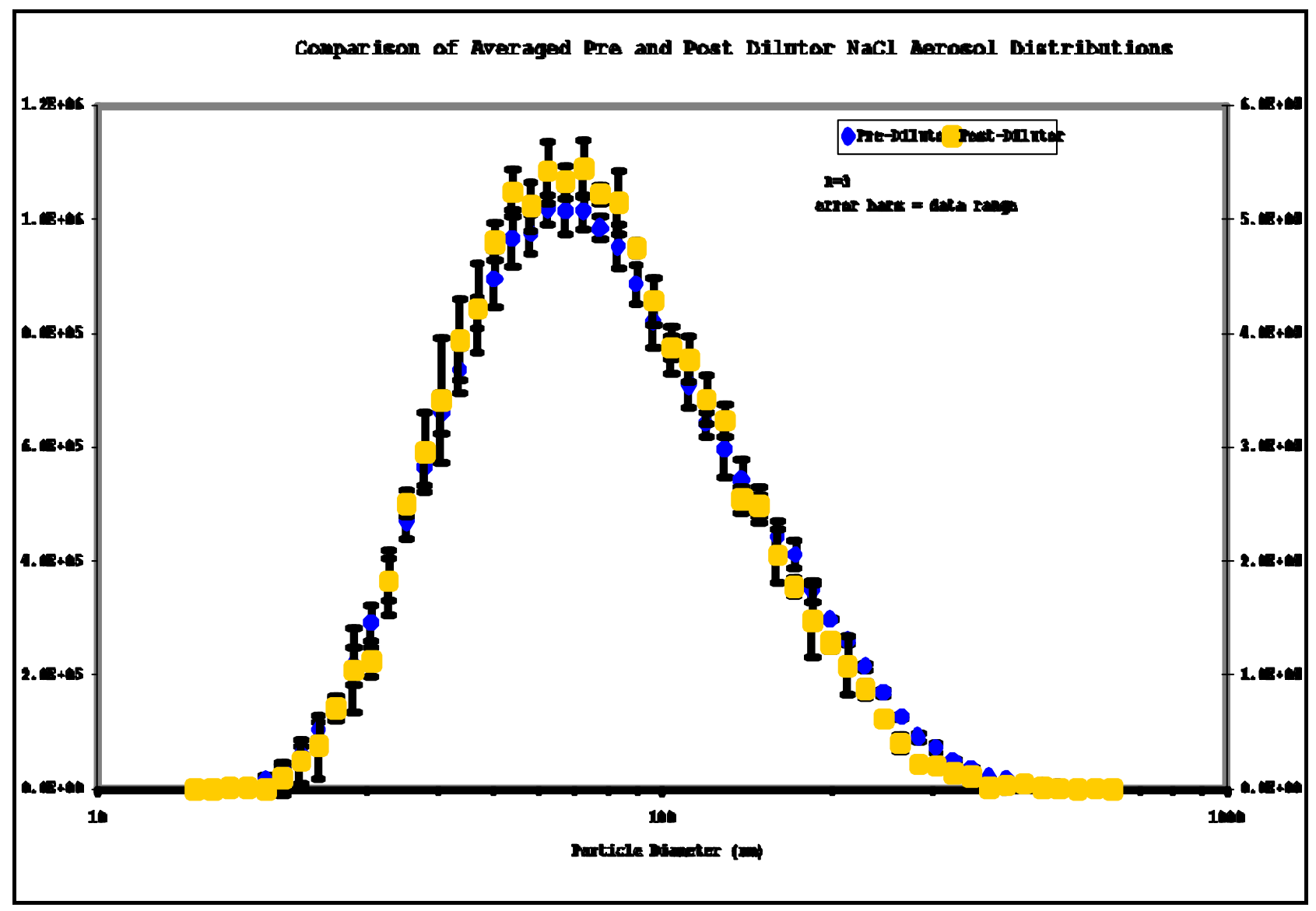

Fig. 4. Particle size distribution for aerosol generated by nebulizing a $0.5 \%(\mathrm{w} / \mathrm{v}) \mathrm{NaCl} / \mathrm{H}_{2} \mathrm{O}$ solution. Both the pre and post dilutor distributions are plotted. The data points represent the mean and the error bars the range of three samples. 
Table 2. Summary statistics of DOP and $\mathrm{NaCl}$ particle size distribution

\begin{tabular}{|c|c|c|c|c|l|}
\hline $\begin{array}{c}\text { Run } \\
\text { Number }\end{array}$ & $\begin{array}{c}\text { Median } \\
(\mathrm{nm})\end{array}$ & $\begin{array}{c}\text { Geo. Mean } \\
(\mathrm{nm})\end{array}$ & $\begin{array}{c}\text { Geo. Stand. } \\
\text { Dev. }\end{array}$ & $\begin{array}{c}\text { Total Con. } \\
(\# / \mathrm{cm} 3)\end{array}$ & \multicolumn{1}{|c|}{ Comment } \\
\hline $2-24.013$ & 68.901 & 67.621 & 1.505 & $3.143 \mathrm{E} 4$ & Pre-diluter Run 1 \\
\hline $2-24.014$ & 69.693 & 68.852 & 1.501 & $4.372 \mathrm{E} 4$ & Pre Run 2 \\
\hline $2-24.015$ & 68.562 & 67.892 & 1.500 & $4.923 \mathrm{E} 4$ & Pre Run 3 \\
\hline $2-24.016$ & 70.376 & 69.205 & 1.491 & $4.901 \mathrm{E} 4$ & Pre Run 4 \\
\hline & & & & & \\
\hline $2-24.018$ & 68.165 & 66.988 & 1.531 & $2.150 \mathrm{E} 3$ & Post-diluter Run 1 \\
\hline $2-24.019$ & 68.787 & 69.791 & 1.544 & $1.975 \mathrm{E} 3$ & Post Run 2 \\
\hline $2-24.020$ & 68.199 & 67.337 & 1.505 & $2.457 \mathrm{E} 3$ & Post Run 3 \\
\hline
\end{tabular}

\begin{tabular}{|c|c|c|c|c|c|}
\hline $\begin{array}{c}\text { Run } \\
\text { Number }\end{array}$ & $\begin{array}{c}\text { Median } \\
(\mathrm{nm})\end{array}$ & $\begin{array}{c}\text { Geo. Mean } \\
(\mathrm{nm})\end{array}$ & $\begin{array}{c}\text { Geo. Stand. } \\
\text { Dev. }\end{array}$ & $\begin{array}{c}\text { Total Con. } \\
\left(\# / \mathrm{cm}^{3}\right)\end{array}$ & Comment \\
\hline $2-23.035$ & 72.744 & 76.241 & 1.777 & $6.557 \mathrm{E5}$ & Pre-Run 1 \\
\hline $2-23.036$ & 74.298 & 77.755 & 1.742 & $6.513 \mathrm{E} 5$ & Pre-Run 2 \\
\hline $2-23.037$ & 74.142 & 77.490 & 1.753 & $6.770 \mathrm{E} 5$ & Pre-Run 3 \\
\hline & & & & & \\
\hline $2-23.045$ & 71.152 & 73.533 & 1.708 & $3.311 \mathrm{E} 4$ & Post-Run 1 \\
\hline $2-23.046$ & 72.951 & 75.542 & 1.689 & $3.254 \mathrm{E} 4$ & Post-Run 2 \\
\hline $2-23.047$ & 74.029 & 76.680 & 1.684 & $3.110 \mathrm{E} 4$ & Post-Run 3 \\
\hline
\end{tabular}

Fig. 5 shows the coefficient of variation (CV) for the pre and post dilutor data. The CV was calculated as

$$
\mathrm{CV}=\left[\left(\sqrt{\frac{\sum\left(\mathrm{N}_{j}-\overline{\mathrm{N}}\right)^{2}}{\mathrm{M}-1}}\right) / \frac{\sum\left(\mathrm{N}_{j}-\overline{\mathrm{N}}\right)}{\mathrm{M}}\right] * 100 \%
$$

where $\mathrm{N}_{\mathrm{j}}$ is the $\mathrm{j}^{\text {th }}$ count for a size bin, the subscript $\mathrm{j}$ is the index for measurement, and $\mathrm{N}$ bar is the average of $N_{j}, M$ is the number of measurement from 1 to a max of 3 . The CV value in Fig. 5 indicates the variation of particle count in the repeated measurements. The 3-sample CV for both the pre and post dilutor data is less than $10 \%$ in the central region of the size distribution where the particle concentration is high as seen in Fig. 4. The areas where the CV exceeds $20 \%$ correspond to the tail ends of the size distribution where the particle counts are low (Fig. 4). This indicates that it is safer to compare the pre- and post-diluter data for $\mathrm{NaCl}$ particles of diameter between 30 and $350 \mathrm{~nm}$.

If turbulence mixing and shear force within the ejector have any effect on particle size, it could cause an increase in the variability of the post dilutor data. If this is the case, examining the difference in the $\mathrm{CV}$ for the pre- and post-dilutor data could yield some information regarding the impacts. A plot of the post-dilutor CV minus the pre-dilutor CV for each particle size range is shown in Fig. 6. This plot shows the variation of particle counts for the individual size bin. When 


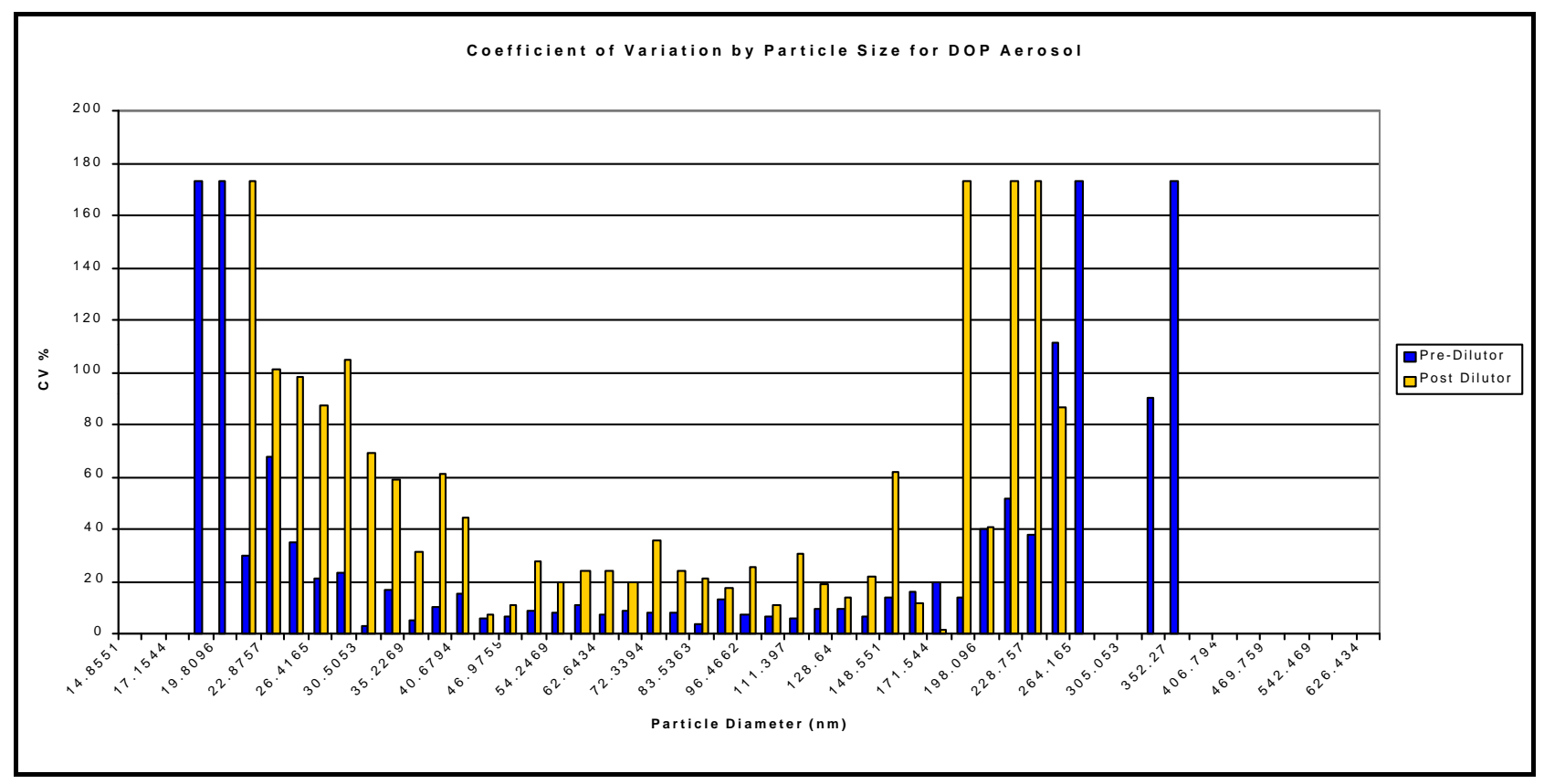

Fig. 5. Coefficient of variation for each particle size range is plotted for both the pre and post dilutor $\mathrm{NaCl}$ aerosol data. The variability in the data is greatest for the size ranges with low concentrations.

$\mathrm{NaCl}$ Aerosol

Difference in Coefficient of Variation Between

Post-Dilutor and Pre-Dilutor Aerosol Concentrations

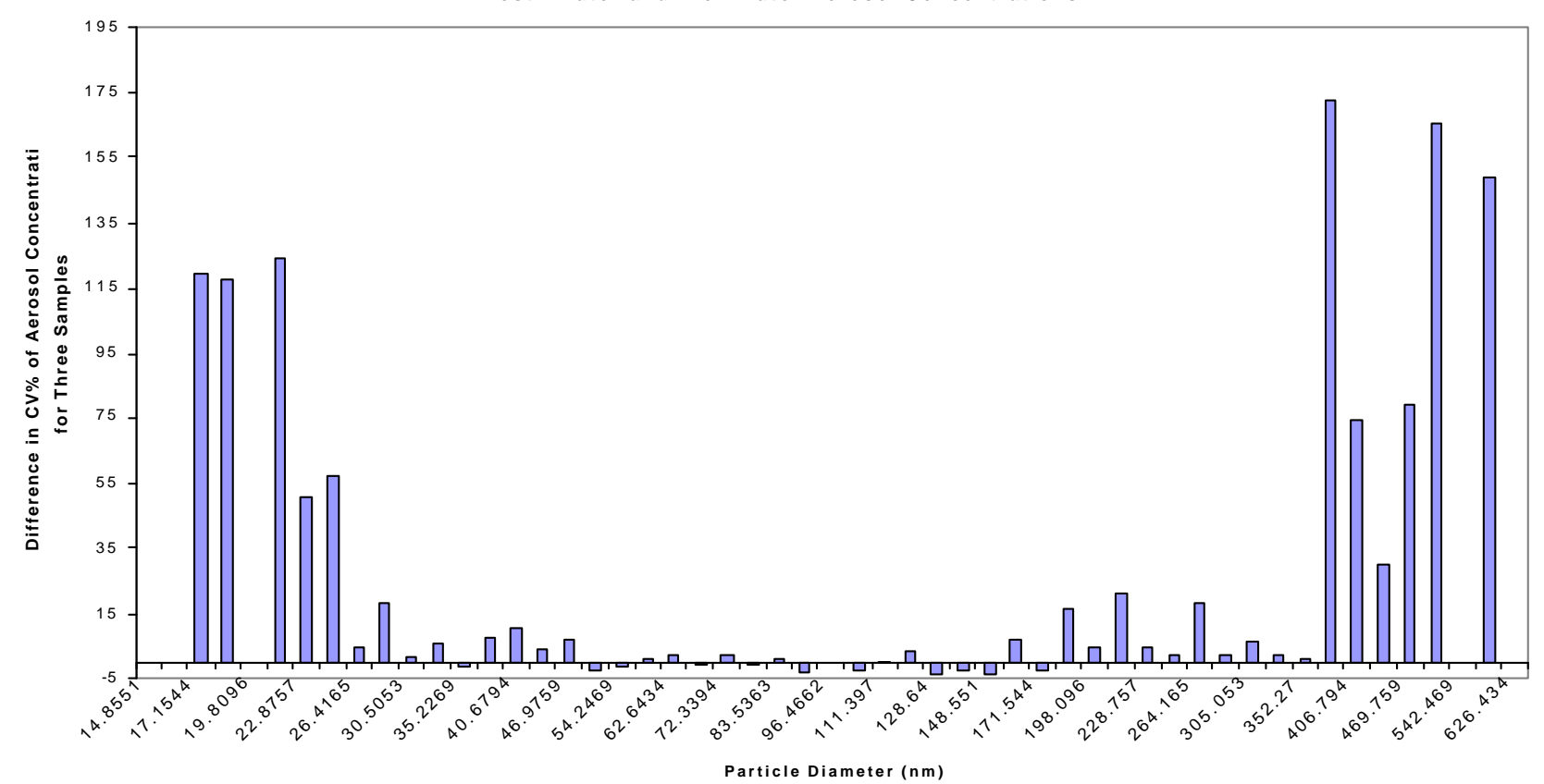

Fig. 6. A plot of the difference in the coefficient of variation between the post and pre dilutor $\mathrm{NaCl}$ Aerosol data in Fig. 5. The differences are small and fluctuate in both the positive and negative direction at the center of the plot where the particle concentrations are the highest. The large positive differences at both ends of the plot correspond to low concentrations of particles after dilution in those size ranges. 
compared with Fig. 5 that shows a similar pattern, it can be seen that the regions of large difference in variability correspond to the tail ends of the distribution while the particle counts were low.

The large differences in these tail regions are most likely caused by low CPC counts. A high Poisson counting error could be resulted from a low count because the theoretical Poisson error is proportional to ON/N. This error is not to be confused and compared with the CV calculated from the repeated measurements. Since the samples for CV calculation are not from a Poisson distribution, it does not make sense to compare (in a sense performing a statistical inference test) the CV value to the Poisson error. The particle counts are found to be higher in the central region than in the tail regions of the distribution in Fig. 4. A high particle count corresponds to a lower Poisson error indicating a better measurement for the central portion of the distribution. Improvement of the SMPS measurement precision at the tail ends can be achieved by increasing the counting time or the scanning time of the instrument that typically leads to higher counts.

The skewness measure of the $\mathrm{NaCl}$ particle size distribution ranges from 0.279 to 0.520 for the pre-diluter data and 0.335 to 0.407 for the post-diluter data. The degree of asymmetry of a distribution is measured by the skewness index that is the $3^{\text {rd }}$ moment of a distribution. The index is zero for a symmetrical distribution. If the distribution has a longer tail less than the maximum, the distribution has negative skewness. Otherwise, it has positive skewness. These results combined with the previous results indicate that the ejector did not significantly modify the overall $\mathrm{NaCl}$ particle size distributions. Thus, based on the statistics examined, we conclude that for the dry $\mathrm{NaCl}$ particles measured there is no discernible difference in the pre- and post-dilutor data. This indicates that the dilutor had no detectable adverse impacts on the $\mathrm{NaCl}$ aerosol in the size range of 30 to 350 $\mathrm{nm}$.

\section{DIOCTYL-PHTHALATE (DOP) PARTICLES}

Oil particles made of DOP are spherical in shape in contrast to the cubic shape of $\mathrm{NaCl}$ particles discussed earlier; the aerodynamics of these 2 aerosols are different which may affect their transport in the turbulence flow in the ejector. Furthermore, the integrity and/or surface tension to maintain the particle integrity of DOP particles in turbulence is intuitively weaker than that of $\mathrm{NaCl}$. We thus expect different DOP particle size distributions before and after the ejector.

The pre- and post-dilutor size distributions for the DOP aerosol are shown in Fig. 7. The size-normalized particle concentration values $\left[\mathrm{dW} / \mathrm{dlog}\left(D_{p}\right)\right]$ plotted in Fig. 7 represent the average of 3 sample runs and the error bars represent the data range computed as the difference between the max value of the 3 samples and the min value. The DOP aerosol concentrations are about an order of magnitude lower than the $\mathrm{NaCl}$ aerosol concentrations shown in Fig. 4, possibly because the solute concentration $(\mathrm{V} / \mathrm{V})$ of $\mathrm{DOP}$ was $0.03 \%$ while that for $\mathrm{NaCl}$ was $0.5 \%(\mathrm{~W} / \mathrm{V})$. It is clear that the size of the error bars in Fig. 7 for the DOP particles is greater than that of the $\mathrm{NaCl}$ particles shown in Fig. 4. The geometric mean size of the DOP particles was $68.4 \mathrm{~nm}$ before and $68.0 \mathrm{~nm}$ after the ejector with a geometric standard deviation of 1.499 before and 1.527 after. The changes of the geometric mean size and geometric standard deviation for the pre- and post- ejector data are statistically insignificant. 


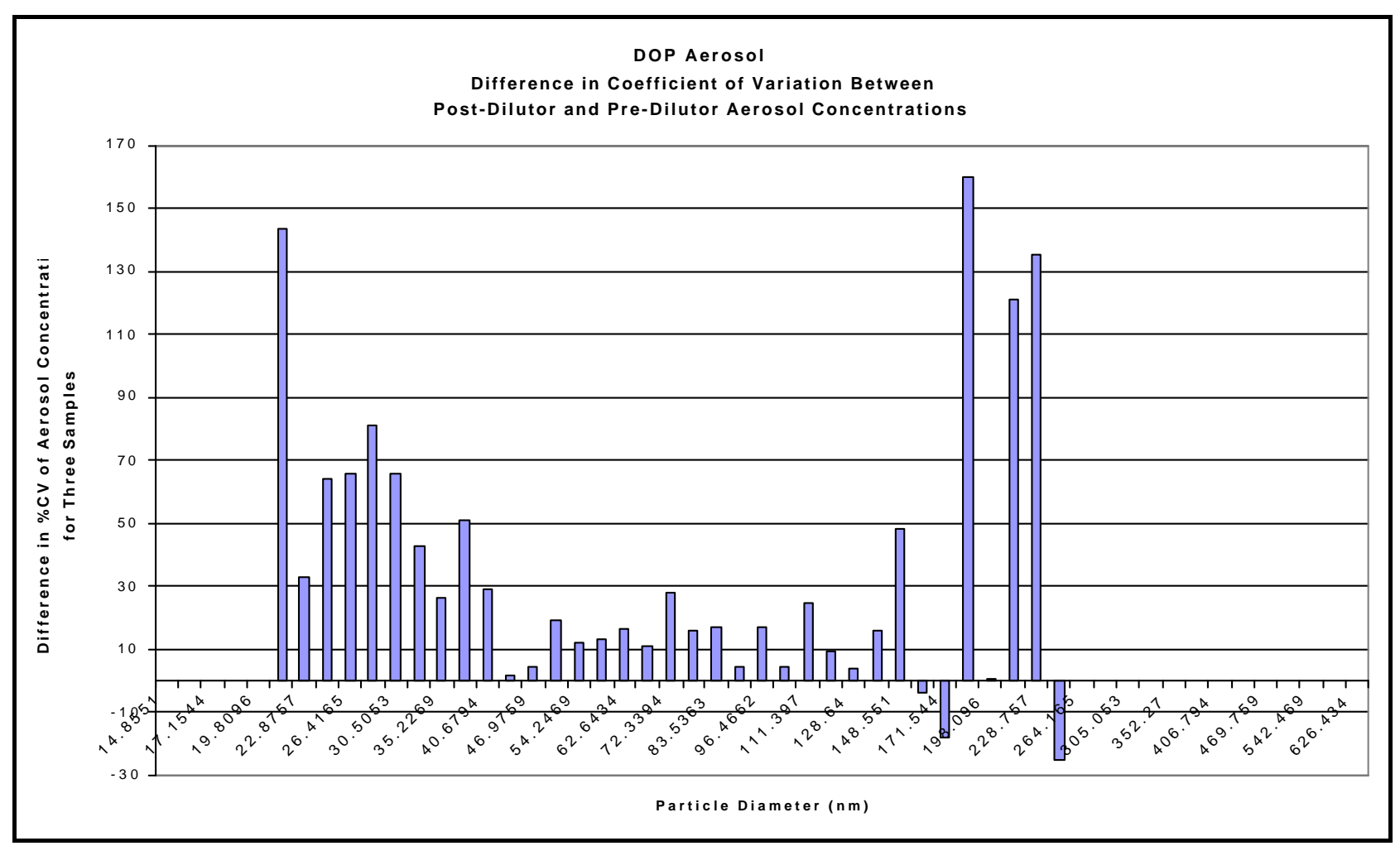

Fig. 7. Particle size distribution for aerosol generated by nebulizing a $0.03 \%(\mathrm{v} / \mathrm{v}) \mathrm{DOP} /$ propanol solution. Both the pre and post dilutor distributions are plotted. The data points represent the mean and the error bars represent the range of three samples.

Similar observation is drawn from the median diameter, while the total number concentration after the ejector was decreased by approximately 20 times as expected again. The skewness ranges from -0.010 to 0.211 for the pre-diluter data and -0.165 to 0.149 for the post-diluter data. The amplification of skewness by the ejector is obvious even the first and second moments (i.e., the mean and standard deviation) do not indicate so. The change of sign in the skewness among different runs indicates the particle size was skewed toward a reverse direction from one run to another. We believe that the ejector could complicate the input particle size distribution even further when the distribution is multi-modal in real particles instead of uni-modal like the test particles we generated, because it would be hard to ensure then if all the moments would be conserved/constant across the ejector.

A plot of the coefficient of variation (CV) for each particle size is shown in Fig. 8. The values of $\mathrm{CV}$ across the size spectrum for the DOP particles are generally larger than that for the $\mathrm{NaCl}$ particles shown in Fig. 5. The $\mathrm{CV}$ in the central region of the curve for $\mathrm{NaCl}$ is less than $10 \%$ for $\mathrm{Dp}$ between 30 and $350 \mathrm{~nm}$, while that for DOP is between 20 and $40 \%$ for Dp between 40 and $150 \mathrm{~nm}$. The results indicate the ejector possibly had a larger adverse impact on the DOP particles than on the $\mathrm{NaCl}$ particles. 


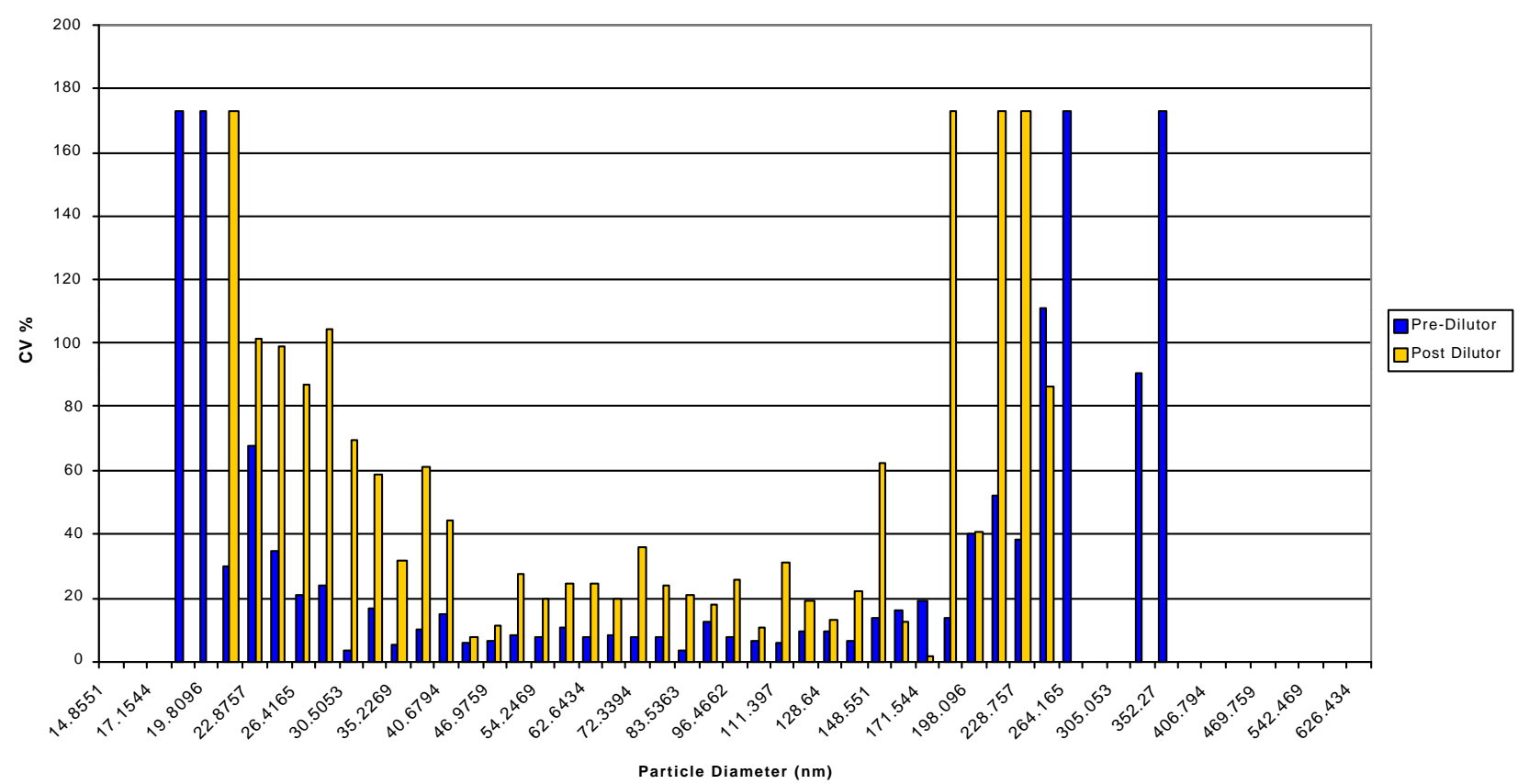

Fig. 8. Coefficient of variation for each particle size range plotted for both the pre and post dilutor DOP aerosol data. The variability in the data is greatest for the size ranges with low concentrations.

\section{CONCLUSIONS}

The purpose of this investigation was to determine if turbulence created by the ejector in the mini-dilutor changes the size of particles passing through it. The results of the $\mathrm{NaCl}$ aerosol experiments show no discernible difference in the geometric mean diameter and geometric standard deviation of particles passing through the ejector. Similar results were found for the DOP particles. The ratio of the total number concentrations before and after the ejector indicates that a dilution ratio of approximately 20 applies equally for $\mathrm{DOP}$ and $\mathrm{NaCl}$ particles. This indicates the dilution capability of this ejector is not affected by the particle composition. The statistical analysis results of the first and second moments of a distribution indicate that the ejector may not change the major parameters (e.g., the geometric mean diameter and geometric standard deviation) characterizing the size distributions of $\mathrm{NaCl}$ and DOP particles.

However, when the skewness was examined, it indicates that the ejector modifies the particle size distribution significantly. The ejector could change the skewness of the distribution in an unpredictable and inconsistent manner. Furthermore, when the variability of particle counts in individual size ranges as a result of the ejector is examined, one finds that the variability is greater for DOP particles in the size range of $40-150 \mathrm{~nm}$ than for $\mathrm{NaCl}$ particles in the size range of 30 to 
$350 \mathrm{~nm}$. The numbers or particle counts in this size region are high enough that the Poisson counting errors are small $(<10 \%)$ compared with the tail regions. This result shows that the ejector device could have a higher bin-to-bin counting uncertainty for "soft" particles such as DOP than for a solid dry particle like $\mathrm{NaCl}$. The results suggest that it may be difficult to precisely characterize the size distribution of particles ejected from the mini-dilution system if the particle is not solid.

\section{REFERENCES}

Abdul-Khalek, I. S., D. B. Kittelson, B. R. Graskow, Q. Wei, and F. Brear. 1998. Diesel exhaust particle size: Measurement issues and trends. Soc. Automot. Eng., [Spec. Publ.], SP-1326 (In-Cylinder Diesel Particulate and NOx Control), 133-145.

Dockery D. and A. Pope. 1996. Epidemiology of acute health effects: Summary of time-series studies. In: R. Wilson and J. D. Spengler, eds. Particles in Our Air: Concentrations and Health Effects. Harvard University Press, Boston.

Graskow, B. R., D. B. Kittelson, M. R. Ahmadi, and J. E. Morris. 1999. Exhaust particulate emissions from two port fuel injected spark ignition engines. Soc. Automot. Eng., [Spec. Publ.], SP-1427 (InCylinder Diesel Particulate and NOx Control 1999), 151-160.

Graskow, B. R., D. B. Kittelson, I. S. Abdul-Khalek, M. R. Ahmadi, and J. E. Morris. 1998.

Characterization of exhaust particulate emissions from a spark ignition engine, Soc. Automot. Eng., [Spec. Publ.], SP-1326 (In-Cylinder Diesel Particulate and NOx Control), 155-164.

Knutson, E. O., and K. T. Whitby. 1975. Aerosol classification by electrical mobility: apparatus theory and applications. J. Aerosol Sci. 6:443.

Pope, C. A., III. 2000. Review: Epidemiological basis for particulate air pollution health standards. Aerosol Sci. Technol. 32:4.

TSI Incorporated. 1999. Model 3936 SMPS (Scanning Mobility Particle Sizer), Instruction Manual, St. Paul, Minn.

USEPA (U.S. Environmental Protection Agency). 1997. National Ambient Air Quality Standards for Particulate Matter; Final Rule. Federal Register, July 18, 1997. 
ORNL/TM-2000/181

\section{INTERNAL DISTRIBUTION}

1-5. M. D. Cheng, 1505, MS-6038

6. R. L. Graham, 1505, MS-6036

7. R. L. Graves, 9108, MS- 8087

8. W. F. Harris, 4500 N, MS-6253

9. S. G. Hildebrand, 1505 , MS-6037

10. G. K. Jacobs, 1505, MS-6035
11. J. M. Loar, 1505, MS-6036

12-16. J. M. Storey

17-19. ESD Library

20-21. ORNL Laboratory Records-OSTI

22. ORNL Laboratory Records-RC

\section{EXTERNAL DISTRIBUTION}

23. Jerry Elwood, Acting Director, Environmental Sciences Division, SC-74, Department of Energy, 19901 Germantown Road, Germantown, MD 20874

24. J. P. Giesy, College of Natural Science, Department of Zoology, Michigan State University, 203 Natural Science Building, East Lansing, MI 48824-1115

25 A. A. Lucier, National Council of the Paper Industry For Air and Stream Improvement, Inc., P.O. Box 13318, Research Triangle Park, NC 27709-3318

26. G. J. Malosh, ORNL Site Manager, Department of Energy, Oak Ridge National Laboratory, P.O. Box 2008, Oak Ridge, TN 37831-6269

27. L. Robinson, Director, Environmental Sciences Institute, Florida A\&M University, Science Research Facility, 1520 S. Bronough Street, Tallahassee, FL 32307

28. J. M. Tiedje, University Distinguished Professor and Director, Center for Microbial Ecology, Michigan State University, 540 Plant and Soil Sciences Building, East Lansing, MI 48824

\section{ELECTRONIC NOTIFICATION}

29. Da-Ren Chen, chenx023@maroon.tc.umn.edu

30. Michael Gurevich, Michael.Gurevich@ee.doe.gov

31. Gurpreet Singh, Gurpreet.Singh@ee.doe.gov 